\title{
Сравнительное исследование фотоэлементов на основе кремния, легированного никелем различными методами
}

\author{
(C) К.А. Исмайлов ${ }^{1}$, Н.Ф. Зикриллаев ${ }^{2}$, С.В. Ковешников ${ }^{2}$, Е.Ж. Косбергенов ${ }^{1, \text { Ф }}$ \\ ${ }^{1}$ Каракалпакский государственный университет, \\ 230112 Нукус, Узбекистан \\ ${ }^{2}$ Ташкентский государственный технический университет, \\ 100095 Ташкент, Узбекистан \\ ฯ E-mail: ernazar.kosbergenov@gmail.com
}

Поступила в Редакцию 11 ноября 2021 г.

В окончательной редакции 17 декабря 2021 г.

Принята к публикации 17 декабря 2021 г.

\begin{abstract}
Сравнивались параметры фотоэлементов на основе кремния, легированного примесными атомами никеля методами диффузии и при выращивании. Установлено, что фотоэлементы, легированные примесными атомами никеля при выращивании кремния, имеют улучшение параметров, сравнимое с полученным методом диффузионного легирования. Дополнительная термообработка при $T=800^{\circ} \mathrm{C}$ позволяет заметно улучшить основные параметры фотоэлементов.
\end{abstract}

Ключевые слова: кремний, фотоэлемент, никель, термообработка, диффузия.

DOI: $10.21883 /$ FTP.2022.04.52200.9768

\section{1. Введение}

Для повышения эффективности фотоэлементов (ФЭ) на основе кремния используются различные методы. Один из методов - геттерирование примесей, ухудшающих время жизни неосновных носителей заряда [1-4]. Показано [5-8], что, формируя кластеры атомов никеля в решетке кремния, можно осуществить геттерирование различных быстро диффундирующих и неконтролируемых примесей.

В работах [9-13] показано, что легирование примесными атомами никеля диффузионным методом кремниевого ФЭ приводит к улучшению его эффективности за счет геттерирующих свойств кластеров никеля. Однако такой способ (диффузионное легирование кремния никелем) улучшения параметров ФЭ требует нескольких технологических операций, таких как химическая очистка до и после диффузии никеля, напыление никеля (или химическое осаждение никеля), диффузионный отжиг и др. [5,7,9].

В связи с этим заслуживает внимания исследование $\Phi Э$ на основе кремния, легированного никелем при выращивании кристалла. Цель данной работы заключалась в сравнении параметров ФЭ на основе кремния, легированного никелем методами диффузии и при выращивании.

\section{2. Экспериментальные результаты и обсуждение}

На рисунке показана технологическая схема получения опытных образцов ФЭ. В качестве исходного материала для изготовления ФЭ использовались кремниевые пластины трех групп.
- Группа $1(\mathrm{Si})$ - кремний (без никеля) - типа с удельным сопротивлением $\rho \sim 40$ Ом · см (КДБ-40).

- Группа $2\left(\mathrm{Si}_{\text {diff }}\right)$ - кремний, легированный никелем по диффузионной технологии. Для этого на поверхность кремниевых образцов (такими же параметрами, как у образцов группы 1) в вакууме напылялся слой чистого никеля толщиной 1 мкм, и проводилась диффузия никеля при оптимальной температуре $T=850^{\circ} \mathrm{C}$, в течение $t=30$ мин [8].

- Группа 3 ( $\left.\mathrm{Si}_{\text {growth }}\right)$ - кремний, легированный никелем в процессе выращивания, $p$-типа с удельным сопротивлением $\rho \sim 70$ Ом · см (КДБ-70).

Параметры исходных образцов всех трех групп, измеренные методом эффекта Холла, показаны в табл. 1. Из табл. 1 видно, что параметры образцов не отличаются друг от друга существенно.

Перед диффузией фосфора образцы всех групп размером $0.8 \times 5 \times 10$ мм подвергались химической очистке (в $10 \% \mathrm{HCl}$, затем в 10\% HF). Диффузия фосфора осуществлялась при $T=1000^{\circ} \mathrm{C}$ в течение $t=30$ мин, при этом глубина $p$-перехода составляла 0.6-0.8 мкм. В образцах 2 группы диффузия фосфора проводилась в „никелевую“ сторону образца. После диффузии каждая

Таблица 1. Параметры исходных материалов для образцов 1,2 и 3 групп

\begin{tabular}{l|c|c|c}
\hline \multicolumn{1}{c|}{ Группа } & $\begin{array}{c}\text { Тип } \\
\text { проводимости }\end{array}$ & $\begin{array}{c}\text { Концентрация } \\
p, \mathrm{~cm}^{-3}\end{array}$ & $\begin{array}{c}\text { Холловская } \\
\text { подвижность } \\
\mu, \mathrm{cm}^{2} /(\mathrm{B} \cdot \mathrm{c})\end{array}$ \\
\hline Группа 1 $(\mathrm{Si})$ & $p$ & $4.7 \cdot 10^{14}$ & 320 \\
Группа 2 $\left(\mathrm{Si}_{\text {diff }}\right)$ & $p$ & $4.7 \cdot 10^{14}$ & 335 \\
Группа 3 $\left(\mathrm{Si}_{\text {growth }}\right)$ & $p$ & $2.8 \cdot 10^{14}$ & 310
\end{tabular}




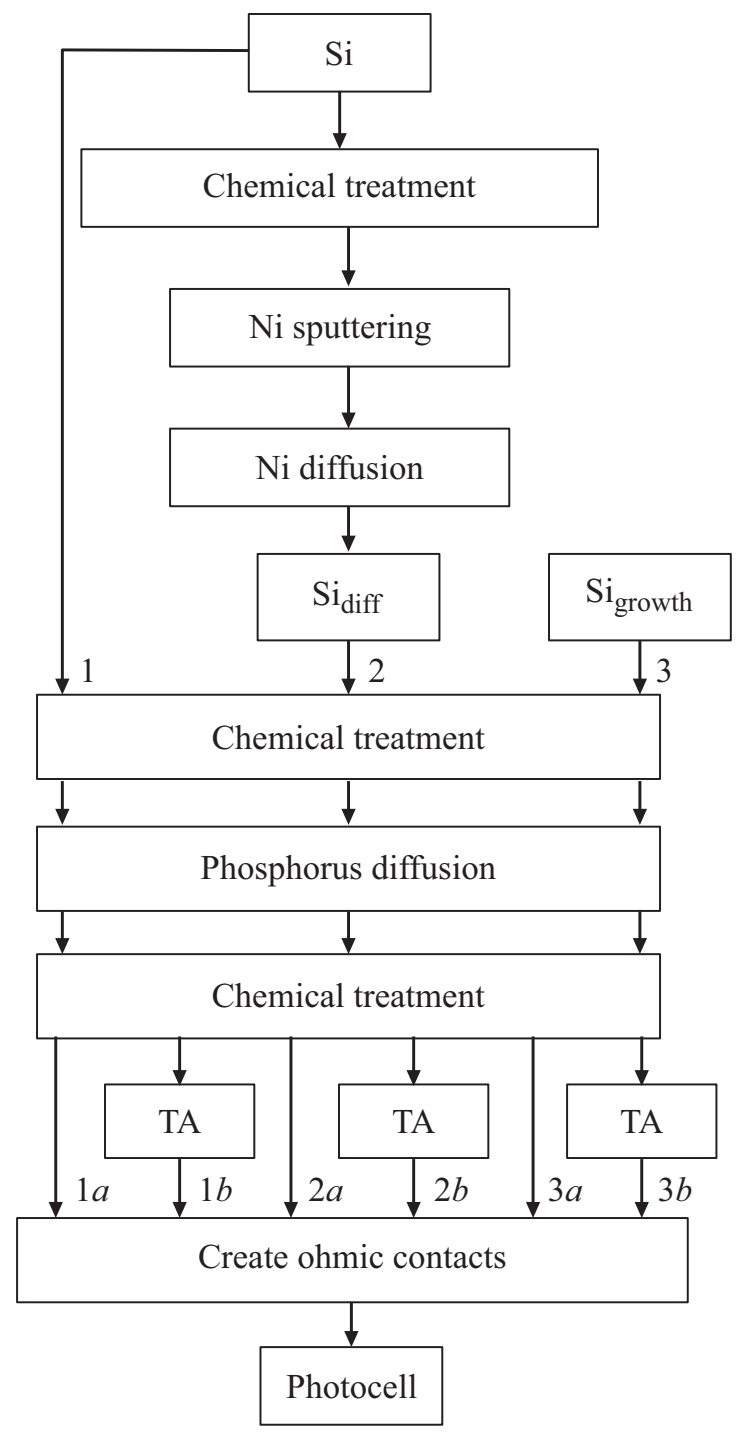

Технологическая схема получения опытных образцов ФЭ.

группа образцов делились на две подгруппы (подгруппы $1 a, 1 b ; 2 a, 2 b ; 3 a, 3 b)$, и образцы подгруппы $b$ дополнительно отжигались (этап „ТА“ - Thermal annealing) при $T=800^{\circ} \mathrm{C}$ в течение $t=30$ мин для активизации процессов геттерирования кластерами никеля [8].

После создания омических контактов были измерены ВАХ $Ф Э$ и определены параметры $Ф Э$ подгруппы „, $a^{\text {“ }}$ (табл. 2). По ВАХ ФЭ определялись средние значения параметров ФЭ и их относительные изменения: $V_{o c}$ - напряжение холостого хода; $\left(V_{o c}-V_{o c 1}\right) / V_{o c 1}-$ относительное изменение напряжения холостого хода (относительно среднего значения для образцов группы $1 a) ; J_{s c}-$ плотность тока короткого замыкания; $\left(J_{s c}-J_{s c 1}\right) / J_{s c 1}$ - изменение плотности тока короткого замыкания (относительно среднего значения для образцов группы $1 a) ; P_{\text {peak }}-$ удельная пиковая мощность (вычисляется как произведение $J_{s c}$ на $V_{o c}$ ); $\left(P_{\text {peak }}-P_{\text {peak } 1}\right) / P_{\text {peak } 1}-$ относительное изменение удель-
Таблица 2. Средние значения параметров ФЭ для образцов подгруппы „,“ и их относительные изменения

\begin{tabular}{l|c|c|c}
\hline \multicolumn{1}{c|}{ Группа } & $1 a$ & $2 a$ & $3 a$ \\
\hline$V_{o c}, \mathrm{MB}$ & 377 & 397 & 400 \\
$\left(V_{o c}-V_{o c 1}\right) / V_{o c 1}, \%$ & - & 5.3 & 6.1 \\
$J_{s c}, \mathrm{MA} / \mathrm{cm}^{2}$ & 17 & 18.2 & 17.8 \\
$\left(J_{s c}-J_{s c 1}\right) / J_{s c 1}, \%$ & - & 7 & 4.7 \\
$P_{\text {peak }}, \mathrm{MBT} / \mathrm{cm}^{2}$ & 6.4 & 7.2 & 7.1 \\
$\left(P_{\text {peak }}-P_{\text {peak } 1}\right) / P_{\text {peak } 1}, \%$ & - & 12.5 & 10.9
\end{tabular}

Таблица 3. Средние значения параметров ФЭ для образцов

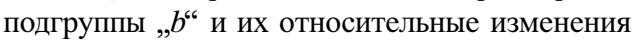

\begin{tabular}{l|c|c|c}
\hline \multicolumn{1}{c|}{ Группа } & $1 b$ & $2 b$ & $3 b$ \\
\hline$V_{o c}, \mathrm{MB}$ & 383 & 412 & 423 \\
$\left(V_{o c}-V_{o c . a}\right) / V_{\text {oc.a }}, \%$ & 1.6 & 3.8 & 5.7 \\
$J_{s c}, \mathrm{MA} / \mathrm{cm}^{2}$ & 17.5 & 19.7 & 19.3 \\
$\left(J_{s c}-J_{s c . a}\right) / J_{s c . a}, \%$ & 3 & 8.2 & 8.4 \\
$P_{\text {peak }}, \mathrm{MBT} / \mathrm{cm}^{2}$ & 6.7 & 8.1 & 8.2 \\
$\left(P_{\text {peak }}-P_{\text {peak.a }}\right) / P_{\text {peak.a }}, \%$ & 4.7 & 12.5 & 15.5
\end{tabular}

ной пиковой мощности (относительно среднего значения для образцов группы $1 a)$.

Параметры ФЭ были достаточно низкими из-за высокого объемного сопротивления базы [14] и большой толщины образцов $[15,16]$.

Как видно из табл. 2, в образцах группы $2 a$ значение $V_{o c}$ увеличивается на $5.3 \%$ (относительно среднего значения $V_{o c}$ группы $1 a$ ), а значение $J_{s c}$ увеличивается более заметно - на 7\%, т. е. наблюдается заметное улучшение параметров ФЭ. В образцах группы $3 a$ среднее значение $V_{o c}$ по отношению к таковому для группы $1 a$ увеличивается на $6.1 \%$, а $J_{s c}-$ на $4.7 \%$.

На основе полученных результатов можно утверждать, что легирование примесными атомами никеля при выращивании кремния приводит к улучшению параметров $V_{o c}$ и $J_{s c}$ ФЭ по сравнению с методом диффузионного легирования. Дальнейшее улучшение параметров $Ф Э$ за счет активации геттерирования требует проведения дополнительного термоотжига. При этом атом рекомбинационной примеси должен освободить узельное состояние в решетке кремния, затем он должен диффундировать к поверхности геттера и, наконец, он должен быть захвачен геттером $[3,4]$.

В табл. 3 представлены основные параметры $\Phi \ni$ группы „b“: $V_{o c}-$ напряжение холостого хода; $\left(V_{o c}-V_{o c . a}\right) / V_{o c . a}$ - относительное изменение напряжения холостого хода (относительно среднего значения для образцов подгруппы „, $\left.a^{\text {c6 }}\right) ; J_{s c}$ - плотность тока короткого замыкания; $\left(J_{s c}-J_{s c . a}\right) / J_{s c . a}-$ изменение плотности тока короткого замыкания (относительно среднего значения для образцов группы , $\left.a^{6}\right) ; P_{\text {peak }}-$ удельная пиковая мощность; $\left(P_{\text {peak }}-P_{\text {peak. } a}\right) / P_{\text {peak. } a}-$ относи- 
тельное изменение удельной пиковой мощности (относительно среднего значения для образцов подгруппы „, $\left.a^{6}\right)$.

Как видно из табл. 3, параметры образцов группы $1 b$ после отжига также увеличивались по сравнению с образцами группы $1 a$. Это можно объяснить геттерирующими свойствами фосфора [17]. Параметры образцов группы $2 b$ существенно изменялись в сторону улучшения. При этом $J_{s c}$ увеличивается по сравнению с образцами группы $2 a$ на $8.2 \%$, а $V_{o c}$ - на $3.8 \%$. Рост пиковой мощности $Ф Э$ группы $2 b$ относительно $1 b$ (контроля) составил 21\%. Очень хорошие результаты были получены на образцах группы $3 b$ : значение $J_{s c}$ увеличивается по сравнению с образцами группы $3 a$ на $8.4 \%$, а значение $V_{\text {oc }}$ растет на $5.7 \%$. Рост пиковой мощности ФЭ группы $3 b$ относительно группы $1 b$ (контроля) составил $22 \%$. Отсюда видно, что диффузионный метод легирования никелем уступает по эффективности легированию при выращивании.

\section{3. Заключение}

Установлено, что в ФЭ, легированных примесными атомами никеля при выращивании кремния с дальнейшей дополнительной термообработкой, происходит заметное (до $22 \%$ по мощности) улучшение их основных параметров.

Легирование кремния никелем при выращивании кристалла позволяет получить большие слитки монокристаллического кремния, равномерно легированные никелем по всему объему, без дополнительных операций и затрат. Такая технология открывает новые возможности для создания дешевых кремниевых ФЭ с повышенной эффективностью.

\section{Благодарности}

Авторы выражают глубокую и искреннюю благодарность проф. М.К. Бахадырханову за ценные советы, данные при выполнении работы и обсуждение полученных результатов.

\section{Конфликт интересов}

Авторы заявляют, что у них нет конфликта интересов.

\section{Список литературы}

[1] M. Seibt, A. Sattler, C. Rudolf, O. Voss, V. Kveder, W. Schroter. Phys. Status Solidi A, 203 (4), 696 (2006).

[2] И.Б. Чистохин, К.Б. Фрицлер. Письма ЖТФ, 46 (21), 11 (2020).

[3] J.S. Kang, D.K. Schroder. J. Appl. Phys., 65, 2974(1989).

[4] C.S. Chen D.K. Schroder. J. Appl. Phys., 71, 5858 (1992).

[5] Б.К. Исмайлов, А.Б. Камалов, Д.Ж. Асанов. Приборы, 252 (6), 25 (2021)

[6] М.К. Бахадирханов, Б.К. Исмайлов. Приборы, 240 (6), 44 (2020).
[7] M.K. Bakhadyrkhanov, B.K. Ismaylov, S.A. Tachilin, K.A. Ismailov, N.F. Zikrillaev. SPQEO, 23 (4), 361 (2020).

[8] M.K. Bakhadyrkhanov, K.A. Ismailov, B.K. Ismaylov, Z.M. Saparniyazova. SPQEO, 21 (4), 392 (2018).

[9] М.К. Бахадырханов, С.Б. Исамов, З.Т. Кенжаев, С.В. Ковешников. Письма ЖТФ, 45 (19), 3 (2019).

[10] М.К. Бахадырханов, 3.Т. Кенжаев. ЖТФ, 91 (6), 981 (2021).

[11] М.К. Бахадырханов, 3.Т. Кенжаев, С.В. Ковешников, К.С. Аюпов, Е.Ж. Косбергенов. ФТП, 56 (1), 128 (2022).

[12] М.К. Бахадырханов, 3.Т. Кенжаев, К.А. Исмайлов, С.В. Ковешников. Гелиотехника, 56 (4), 322 (2020).

[13] М.К. Бахадырханов, З.Т. Кенжаев, Х.С. Турекеев, Б.О. Исаков, А.А. Усмонов. ЖТФ, 91 (11), 1685 (2021).

[14] P. Panek, K. Drabczyk, P. Zięba. Opto-Electronics Rev., 17 (2), 161 (2009).

[15] А.В. Саченко, В.П. Костылев, А.В. Бобыль, В.Н. Власюк, И.О. Соколовский, Г.А. Коноплев, Е.И. Теруков. Письма ЖТФ, 44 (19), 40 (2018).

[16] C.T. Sah, K.A. Yamakawa, R. Lutwack. J. Appl. Phys., 53, 3278 (1982).

[17] N. Khedhera, M. Hajjia, M. Hassena, A. Ben Jaballaha, B. Ouertania, H. Ezzaouiaa, B. Bessaisa, A. Selmib, R. Bennaceur. Solar Energy Mater. \& Solar Cells, 87, 605 (2005).

\section{Comparative study of photocells based on silicon doped with nickel by various methods}

\author{
K.A. Ismailov ${ }^{1}$, N.F. Zikrillaev ${ }^{2}$, S.V. Koveshnikov ${ }^{2}$, \\ E.Zh. Kosbergenov ${ }^{1}$ \\ ${ }^{1}$ Karakalpak State University, \\ 230112 Nukus, Uzbekistan \\ ${ }^{2}$ Tashkent state technical University, \\ 100095 Tashkent, Uzbekistan
}

\begin{abstract}
In this work, the parameters of silicon-based photocells doped with impurity nickel atoms by diffusion methods and during growth were compared. It was found that photocells doped with impurity nickel atoms during silicon growth have an improvement in parameters comparable to that obtained by the diffusion doping method. Additional heat treatment at $T=800^{\circ} \mathrm{C}$ makes it possible to significantly improve their basic parameters.
\end{abstract}

